\title{
Flume Tests on Fine Soil Reinforced with Geosynthetics: Walls of the Salt Pans (Aveiro Lagoon, Portugal)
}

\author{
M. Pinho-Lopes ${ }^{1}$ D. M. Carlos ${ }^{2,3}$ - M. L. Lopes ${ }^{3}$
}

Received: 13 January 2015/Accepted: 20 March 2015/Published online: 1 April 2015

(c) Springer International Publishing AG 2015

\begin{abstract}
This paper presents exploratory work on the use of geosynthetics for reinforcing fine soils, particularly for applications in the Aveiro lagoon, Portugal. The behaviour of local fine soil reinforced with geosynthetics under hydraulic actions was studied using flume tests. The case study was a typical cross section of the walls of the salt pans of the Aveiro lagoon. A preliminary design of a structure was done, for different reinforcements (geogrid, geocomposite, association of geogrid and geotextile). Local soil was collected and characterised using laboratory tests. The flume tests included performing permeability, erosion and overtopping tests, for actions typical of the lagoon environment. The models reinforced with geogrid GGR exhibited the highest global permeability, due to the difficulty of soil lumps to penetrate the geogrid openings. Although this type of reinforcement provides low resistance to erosion, promoting vegetation growth or including other elements can reduce surface erosion. The other reinforcements (sheets) enabled containing the soil. Non-
\end{abstract}

M. Pinho-Lopes

m.pinho-lopes@ soton.ac.uk

D. M. Carlos

dmc@ua.pt

M. L. Lopes

lcosta@fe.up.pt

1 Faculty of Engineering and the Environment, University of Southampton, Highfield, Southampton SO17 1BJ, UK

2 Department of Civil Engineering, University of Aveiro, Campus Universitário de Santiago, 3810-193 Aveiro, Portugal

3 Department of Civil Engineering, Faculty of Engineering, University of Porto, Rua Dr. Roberto Frias, s/n 4200-465, Porto, Portugal uniformity of the soil compaction caused local differences of permeability. Thus, ensuring uniform compaction on site is necessary; however it can be challenging, particularly for fine soils. The results indicate that seepage is likely to induce some clogging of the reinforcements. The reinforced soil models tested exhibited higher permeability and lower resistance to erosion and overtopping than the traditional solution (soil matrix with vegetation). The results indicate that a possible alternative solution for the walls could use fibre reinforcement. Further work is necessary to ensure adequate (low) permeability of new solutions for these walls.

Keywords Geosynthetics · Geogrid · Geocomposite · Geotextile $\cdot$ Reinforced soil $\cdot$ Fine soil $\cdot$ Flume

\section{Introduction}

This paper studies the use of geosynthetics for reinforcing fine soils, particularly for application in the Aveiro lagoon, Portugal. It includes some exploratory work on the behaviour of fine soil reinforced with geosynthetics under hydraulic actions using flume tests.

The production and extraction of salt in the Aveiro lagoon was a thriving activity. However, presently most salt pans are abandoned and their decay promotes further deterioration. For example, traditionally the walls limiting the salt pans were maintained yearly to remove large holes caused by rodents or local erosion during winter. As most salt pans are currently abandoned, such maintenance is no longer done. Additionally, the tide levels, the flow velocities and the salt water rates in the salt pans' area are increasing, due to the increase of the depth of the channel on the lagoon inlet [1]. Recent studies analyse the flood 
hazard on the lagoon $[2,3]$ and the influence of the mean size level rise on the tidal dynamics of the lagoon [4].

Traditionally the salt pans were formed by a core made of mud taken from the interior ground of the salt pan, and an external part, consisting of two opposite walls of blocks of clayey soil $\left(0.20 \times 0.20 \times 0.30 \mathrm{~m}^{3}\right)$ extracted from the surface of the reed fields [1]. This clayey soil had significant amounts of reed (juncus maritimus) with deep and very strong roots. A staged construction process was used, to allow for sufficient consolidation. When the desired height of the wall was reached (enough to protect the salt pan against the higher tide levels expected without overtopping), its surface was covered with a final layer of mud. The width at the top of the walls was about $2.50 \mathrm{~m}$. The traditional solution was characterised by Carlos et al. [1] using flume tests.

The traditional method to build the walls is no longer used. On one hand, this task demands knowledge, great physical effort, time and manpower and nowadays is quite difficult to find workers willing to do such heavy work. On the other hand, the materials necessary to use the traditional solution are scarce, as the environmental changes observed in the area led to the replacement or the complete disappearance of the typical vegetation, crucial for the stability of the walls. The walls then collapse and the strong flow currents that are increasingly penetrating into the Aveiro lagoon further contribute to their destruction.

Carlos et al. [1] presented two alternative designs for these walls: (1) with staked geobags filled with sand and a clayed centre (recreating the traditional solution); (2) reinforced soil with geosynthetics. Carlos and Pinho-Lopes [5] performed an extensive study for solutions using reinforced soil with geosynthetics, collecting design methods (enabling the use of fine soils as backfill material) and relevant properties of local soils. The authors analysed the stability of different solutions for these structures considering two types of fill materials (granular and fine) and different reinforcements. This study was performed for a wall $6.0 \mathrm{~m}$ high (the highest possible, although quite unlikely to occur).

The walls need to prevent water from entering the salt pans. Therefore, their permeability should be low enough. Using local fine soils as backfill materials for new walls can contribute to achieving low enough permeability. However, the structures need to perform well under hydraulic actions typical of the lagoon. Reinforced soil solutions using geosynthetics can minimise surface erosion by using different strategies: avoiding reinforcements with large openings (such as geogrids); using composites as reinforcements (geogrid and geotextile); promoting vegetation growth on the surface; waterproofing the structure. These solutions will have different construction requirements and costs.
In this paper, solutions of fine soil reinforced with different geosynthetics were studied, particularly their performance under hydraulic actions typical of the lagoon (using flume tests). This exploratory work focused on different types of reinforcements; their behaviour under hydraulic actions was compared with that of unreinforced soil. To define the density of reinforcements (length and vertical spacing), a preliminary design of the structure was done for the most common cross section $(3.5 \mathrm{~m}$ high) of the salt pans walls. A comparison with results from similar tests on the traditional material [1] was done; some recommendations for future work and alternative solutions for the walls are put forward.

\section{Reinforced Fine Soil Wall}

\section{Case Study}

The starting point for this work was a particular case study: the walls of the salt pans in the Aveiro lagoon (Portugal), separating the salt pan's reservoirs from adjacent channels. The area is a coastal lagoon (North-western Portuguese coast) with a surface of about $83 \mathrm{~km}^{2}$ at high tide and consists of a web of narrow channels and intertidal flat areas. These are connected to the ocean by one inlet and have semi-diurnal tides (average range $\sim 2 \mathrm{~m}$ ). The salt pans walls have to: ensure adequate permeability (minimising entrance of water in the reservoir); resist erosion associated with the water flow in the channels; resist overtopping in case of such extreme event. In this work, a typical wall cross section (Fig. 1) was analysed using reinforced soil with geosynthetics. The geometry was chosen to match the most common one in the lagoon $(3.5 \mathrm{~m}$ high and $2.5 \mathrm{~m}$ wide at the top).

\section{Reinforcements}

The reinforcements were chosen within a group of materials being studied extensively [6]. Although geogrids are commonly used for soil reinforcement, for this particular case study a major possible drawback was identified: the openings of the geogrid may allow the soil to be eroded from the structure, compromising stability. However, this

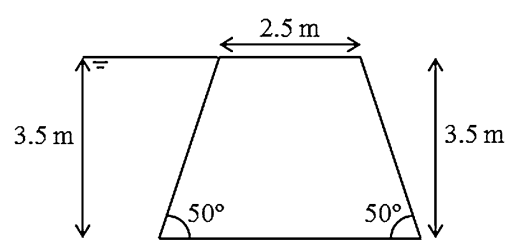

Fig. 1 Generic cross section of the soil reinforced structure analysed 
reinforcement was studied. On one hand, this enables better understanding the impact of using composite reinforcements (geogrid and geotextile) on minimising erosion (by comparing the erosion with and without the introduction of a geotextile adjacent to the geogrid). On the other hand, for solutions where vegetation plays a fundamental role on protecting the structure from surface erosion, it allows assessing the impact of erosion if the vegetation does not grow or is removed at a later stage.

Three different reinforcement solutions were studied: (1) geogrid GGR, woven geogrid composed of high modulus polyester (PET) fibres knitted in a flat orientation and covered with a protective polymeric coating; (2) geocomposite GCR, uniaxial geocomposite composed of high modulus PET fibres attached to a continuous filament nonwoven geotextile backing; (3) geogrid GGR and geotextile GTX (GGR+GTX), association of geogrid GGR with a geotextile (GTX) consisting of continuous thermo-bonded polypropylene (PP) filaments. Table 1 includes relevant nominal

Table 1 Nominal values of properties of the geosynthetics used (from their datasheets)

\begin{tabular}{llllll}
\hline Property & Unit & Test standard & GGR & GCR & GTX \\
\hline Polymer & - & - & PET & PET & PP \\
$T(\mathrm{MD})$ & $\mathrm{kN} / \mathrm{m}$ & EN ISO 10319 [7] & 55 & 55 & 13.1 \\
$T(\mathrm{CMD})$ & $\mathrm{kN} / \mathrm{m}$ & EN ISO 10319 [7] & 55 & 12 & $*$ \\
$\varepsilon(\mathrm{MD})$ & $\%$ & EN ISO 10319 [7] & 10.5 & 10 & 52 \\
$\varepsilon(\mathrm{CMD})$ & $\%$ & EN ISO 10319 [7] & 10 & 85 & $*$ \\
$t$ & $\mathrm{~mm}$ & EN ISO 9863-1 [8] & $*$ & $*$ & 0.57 \\
$\psi$ & $\mathrm{s}^{-1}$ & EN ISO 11058 [9] & $*$ & 1.4 & 0.70 \\
$O_{90}$ & $\mu \mathrm{m}$ & EN ISO 12956 [10] & $*$ & 95 & 80 \\
\hline
\end{tabular}

* Data not available in the technical datasheets of the geosynthetics $M D$ Machine direction, $C M D$ Cross machine direction properties of the geosynthetics (from their datasheets): tensile strength (T), in machine direction (MD) and in cross machine direction (CMD); strain for the tensile strength $(\varepsilon)$, for both machine and cross machine direction; thickness $(t)$; permittivity $(\psi)$; characteristic opening size $\left(O_{90}\right)$ [7-10].

\section{Preliminary Design}

To define the flume tests setup (namely the vertical spacing between consecutive reinforcement layers), a preliminary design of the structure was performed. As this was done at an initial stage of the work, before collecting soil samples for characterisation, the properties of the fine soil considered as backfill material were chosen from the literature. Bonito [11] and Gomes [12] performed extensive tests to characterise typical materials from the Aveiro lagoon. Therefore, two sets of soil properties (identified as $\mathrm{C} 1$ and C2) were estimated $[11,12]$ by considering significant ranges of values for the soil properties, in order to achieve results that represent the study area widely: soil unit weight $(\gamma)$; soil friction angle $\left(\phi^{\prime}\right)$, and cohesion $\left(c^{\prime}\right)$, in effective stresses; and undrained shear strength $\left(c_{\mathrm{u}}\right)$. These were: $\gamma=16 \mathrm{kN} / \mathrm{m}^{3} ; \quad \phi^{\prime}=34^{\circ} \quad(\mathrm{C} 1) \quad$ and $\phi^{\prime}=20^{\circ} \quad(\mathrm{C} 2)$; $c^{\prime}=7 \mathrm{kPa}(\mathrm{C} 1)$ and $c^{\prime}=27 \mathrm{kPa}(\mathrm{C} 2) ; c_{\mathrm{u}}=25 \mathrm{kPa}(\mathrm{C} 1)$ and $c_{\mathrm{u}}=15 \mathrm{kPa}(\mathrm{C} 2)$.

For the preliminary design three different reinforcements were considered (geogrid GGR, geocomposite GCR and GGR+GTX association of geogrid GGR and geotextile GTX). The internal design of the structure followed the method by Rogbeck et al. [13] and Table 2 summarises the results. The design assumed only one type of reinforcement per structure; the length of the reinforcement and the vertical spacing between consecutive layers of reinforcement, necessary to ensure the internal stability of the wall, were defined. The design tensile strength $\left(F_{\mathrm{ult}, \mathrm{d}}\right)$ of the
Table 2 Results of the preliminary internal design: reinforcement length $\left(L_{\mathrm{R}}\right)$ and vertical spacing $\left(e_{\mathrm{v}}\right)$

\begin{tabular}{|c|c|c|c|c|c|c|c|c|}
\hline \multirow[t]{3}{*}{ Reinforcement layer } & \multicolumn{4}{|l|}{ GGR } & \multicolumn{4}{|c|}{ GCR and GGR+GTX } \\
\hline & \multicolumn{2}{|l|}{$\mathrm{C} 1$} & \multicolumn{2}{|l|}{$\mathrm{C} 2$} & \multicolumn{2}{|l|}{$\mathrm{C} 1$} & \multicolumn{2}{|l|}{$\mathrm{C} 2$} \\
\hline & $L_{\mathrm{R}}(\mathrm{m})$ & $e_{\mathrm{v}}(\mathrm{m})$ & $L_{\mathrm{R}}(\mathrm{m})$ & $e_{\mathrm{v}}(\mathrm{m})$ & $L_{\mathrm{R}}(\mathrm{m})$ & $e_{\mathrm{v}}(\mathrm{m})$ & $L_{\mathrm{R}}(\mathrm{m})$ & $e_{\mathrm{v}}(\mathrm{m})$ \\
\hline Base & 2.5 & 0.5 & 7.6 & 0.3 & 2.2 & 0.5 & 6.6 & 0.3 \\
\hline 1 & 2.0 & 0.5 & 2.0 & 0.3 & 2.0 & 0.5 & 2.0 & 0.3 \\
\hline 2 & 2.0 & 0.5 & 2.0 & 0.3 & 2.0 & 0.5 & 2.0 & 0.3 \\
\hline 3 & 2.0 & 0.5 & 2.0 & 0.3 & 2.0 & 0.5 & 2.0 & 0.3 \\
\hline 4 & 2.0 & 0.5 & 2.0 & 0.3 & 2.0 & 0.5 & 2.0 & 0.3 \\
\hline 5 & 2.0 & 0.5 & 2.0 & 0.3 & 2.0 & 0.5 & 2.0 & 0.3 \\
\hline 6 & 2.0 & 0.5 & 2.0 & 0.3 & 2.0 & 0.5 & 2.0 & 0.3 \\
\hline 7 & - & - & 2.1 & 0.3 & - & - & 2.1 & 0.3 \\
\hline 8 & - & - & 2.3 & 0.3 & - & - & 2.3 & 0.3 \\
\hline 9 & - & - & 2.5 & 0.3 & - & - & 2.5 & 0.3 \\
\hline 10 & - & - & 2.6 & 0.3 & - & - & 2.6 & 0.3 \\
\hline 11 & - & - & 2.8 & 0.3 & - & - & 2.8 & 0.3 \\
\hline
\end{tabular}


reinforcement (Eq. 1) was determined from the corresponding characteristic value $\left(F_{\text {ult,k }}\right)$ using: conversion factor for creep $\left(\eta_{1}=0.2\right)$; conversion factor for installation damage $\left(\eta_{2}=0.91\right)$; conversion factor for biological and chemical degradation $\left(\eta_{3}=0.91\right)$; partial safety factor for the soil parameters $\left(\gamma_{M}=1.0\right)$. The external stability of the structure was analysed using EN 1990: 2002 [14], and EN 1997-1: 2004 [15].

$F_{\mathrm{ult}, \mathrm{d}}=F_{\mathrm{ult}, \mathrm{k}} \frac{\eta_{1} \times \eta_{2} \times \eta_{3}}{\gamma_{\mathrm{M}}}$

The smaller vertical spacing between consecutive layers of reinforcement $\left(e_{\mathrm{v}}\right)$ found was $0.3 \mathrm{~m}$ (combination $\mathrm{C} 2$ ). The length of the reinforcement $\left(L_{\mathrm{R}}\right)$ varies, depending on the reinforcement and on the position of the layer within the structure. The values of $L_{\mathrm{R}}$ depend on the strength of the soil-reinforcement interface, usually defined as a ratio to the soil strength. The values for the interaction factor were chosen according to Rogbeck et al. [13], for clay or silt soils: 0.80 for the geogrid GGR (reinforcement with a grid structure) and 0.7 for geocomposite GCR or the association GGR+GTX (sheet reinforcement).

On the top layers, the reinforcement length is larger than the wall width. To guarantee the reinforcements would not fail, when analysing the stability of the structure the forces on the reinforcement layers where checked (ensuring they not exceed the corresponding design value). The wraparound part of the reinforcement is not accounted for in the method; it is expected that such length and its spatial distribution will help mobilising adequate strength.

\section{Experimental Program}

\section{Test Program}

The experimental test program consisted in characterising the different materials used, soil and geosynthetics, and assessing properties of the soil-geosynthetic composite material. The program intended to study a possible solution for building walls of the salt pans, but at the same time contributing to enhance the knowledge on generic structures using reinforced fine soil. Flume tests were performed for the composite material, recreating layers of fine soil reinforced with geosynthetics with a vertical spacing between reinforcement of $0.30 \mathrm{~m}$ (obtained from the preliminary design).

\section{Soil}

Soil was collected from a salt pan and tested (remoulded). The soil was characterised using: oedometer tests (ISO/TS 17892-5: 2004 [16]), to estimate parameters for one- dimensional consolidation; modified Proctor tests ASTM D1557-12 [17], to assess compaction characteristics; triaxial tests (ISO/TS 17892-8: 2004 [18]), to estimate the soil strength; and California Bearing Ratio (CBR) tests (ASTM D1883-07 [19]).

Table 3 summarises soil properties obtained from laboratory tests: percentage of fine particles $(<0.074 \mathrm{~mm})$; average $\left(D_{50}\right)$ and maximum $\left(D_{\max }\right)$ grain sizes; liquid limit $\left(w_{\mathrm{L}}\right)$; plastic limit $\left(w_{\mathrm{P}}\right)$; plasticity index $\left(I_{\mathrm{P}}\right)$; unit weight $(\gamma)$; classification of the soil samples according with ASTM D2487-11 [20] and AASHTO M145-91-UL [21]; coefficient of compressibility $\left(a_{\mathrm{v}}\right)$; coefficient of volume compressibility $\left(m_{\mathrm{v}}\right)$; coefficient of vertical consolidation $\left(c_{\mathrm{v}}\right)$; vertical permeability $\left(k_{\mathrm{v}}\right)$, calculated from Eq. 2, where $\gamma_{\mathrm{w}}$ is the unit weight of water

$k_{\mathrm{v}}=c_{\mathrm{v}} \times m_{\mathrm{v}} \times \gamma_{\mathrm{w}}$.

Figure 2 includes the soil grain size distribution of Samples 1 and 2 . The compression index $\left(C_{\mathrm{c}}\right)$ was 0.34 and 0.33 for samples 1 and 2, respectively; the recompression index $\left(C_{\mathrm{r}}\right)$ was 0.06 and the pre-consolidation effective stress was $58 \mathrm{kPa}$ for both samples (Fig. 3). The optimum laboratory compaction characteristics obtained from the modified Proctor test were $\rho_{\text {dmax }}=1.845 \mathrm{~g} / \mathrm{cm}^{3}$ and $w_{\text {opt }}=13.9 \%$.

For the triaxial tests the soil was compacted to a density of $\rho=2.047 \mathrm{~g} / \mathrm{cm}^{3}$. The internal friction angle of soil $\left(\phi^{\prime}\right)$ and cohesion $\left(c^{\prime}\right)$, for drained conditions and the undrained shear strength $\left(c_{\mathrm{u}}\right)$ were determined: dry samples, $\phi^{\prime}=$ $35.6^{\circ}, \quad c^{\prime}=14.4 \mathrm{kPa}$; saturated samples, $\phi^{\prime}=33.6^{\circ}$, $c^{\prime}=2.7 \mathrm{kPa} ; c_{\mathrm{u}}$ equal to $25.3,36.6$ and $45.5 \mathrm{kPa}$ for confining stresses of 50,100 and $150 \mathrm{kPa}$, respectively. These test results are in good agreement with results from of other studies [11, 12]. Most values used for the preliminary design of the structure are within the range of values determined from the tests, validating the assumptions done at that point.

The $C B R$ values for penetrations of $2.5 \mathrm{~mm}$ and $5.0 \mathrm{~mm}$, respectively, are: $C B R_{2.5 \mathrm{~mm}}=4.67$ and $C B R_{5 \mathrm{~mm}}=4.73$, which are in good agreement with the expected range for this type of soil.

\section{Geosynthetics}

The geosynthetics were characterised using tensile tests (EN ISO 10319:2008 [7]). For geocomposite GCR, permittivity (EN ISO 11058:2009 [9]) and characteristic opening size (EN ISO 12956:1999 [10] were also assessed. The permittivity of the composite formed by the association of geogrid GGR and geotextile GTX was determined. Due to the limited availability of material, geotextile GTX was not tested for permittivity. Table 4 summarises the results of the tests carried out to characterise the geosynthetics studied. 


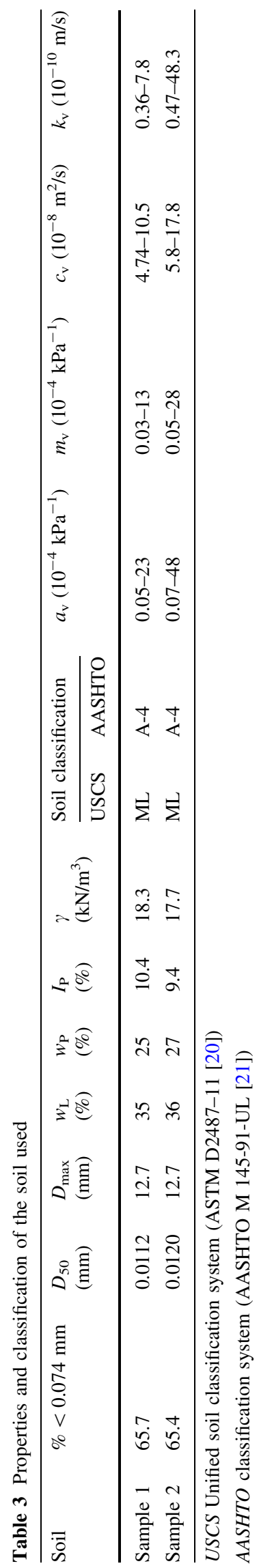

The nominal tensile strength of geogrid GGR $(55 \mathrm{kN} / \mathrm{m})$ is too optimistic, and was not achieved in the laboratory tests (mean value of $44.4 \mathrm{kN} / \mathrm{m}$ ). A similar observation was done for geotextile GTX (nominal value of $13.1 \mathrm{kN} / \mathrm{m}$ and measured mean value of $12.8 \mathrm{kN} / \mathrm{m}$ ). Equally the measured value of the characteristic opening size of geocomposite GCR $(208 \mu \mathrm{m})$ was far from the corresponding nominal value $(95 \mu \mathrm{m})$; although a better approximation was achieved for the permittivity (measured value of $1.27 \mathrm{~s}^{-1} \mathrm{vs}$ a nominal value of $1.4 \mathrm{~s}^{-1}$ ). For the characteristic opening size of geotextile GTX the measured value $(76 \mu \mathrm{m})$ was $5 \%$ smaller than the nominal property $(80 \mu \mathrm{m})$. These trends, which are relatively normal, highlight the need of carrying out tests to characterise geosynthetics as-received, to ensure that the properties used in their design are representative of the materials received.

\section{Soil-Geosynthetic Composite Material}

Flume tests of models of reinforced soil layers were performed by Alves [22]. Their dimensions (and the test setup used) were restricted by those of the available flume $\left(0.50 \times 0.40 \mathrm{~m}^{2}\right.$ cross-section and $10 \mathrm{~m}$ long $)$. To prevent seepage on the walls/model contacts, silicone layers were used on the lateral and bottom surfaces of the flume. The flow rate and the water velocities in the flume were assessed by preliminary characterisation tests. The models were built using plywood frameworks, in order to limit deformations during their construction, simulating realistic constructive sequence. The models and the tests conditions were chosen to enable comparisons with similar data obtained for the material used traditionally to build these walls.

The models reproduce a $0.30 \mathrm{~m}$ high reinforced soil layer of a structure with variable length. Each model consisted of a base soil layer (height $h_{\mathrm{b}}$ ), a reinforced soil layer (height $h_{\mathrm{r}}$ ) and a top soil layer (height $h_{t}$ ), with a total height $(H)$, width $(B)$ and length $(L)$ (Table 5; Fig. 4). Part of the reinforcement (length $l_{\mathrm{a}}$ ) was folded on each end of the model. Three types of tests were performed: permeability (Fig. 4a), lateral and frontal erosion (Fig. 4b) and overtopping (Fig. 4c). For the permeability tests the top soil layer was also reinforced. The model dimensions were adjusted for the different tests carried out. The width of the model (Table 5) corresponds to the distance between its two opposite reinforced faces.

The soil (with the optimum water content) was placed, levelled and compacted (to a density of $\rho=1.845 \mathrm{~g} / \mathrm{cm}^{3}$ ) on the flume using a hammer for Proctor tests $(4.54 \mathrm{~kg}$ mass, $457 \mathrm{~mm}$ drop height, $95 \mathrm{~mm}$ compaction base). The reinforcement layer was wrapped-around the soil, using the reinforcement as facing (Fig. 4b). During the tests a continuous image register was done. After each test the models were disassembled and, in some cases, the geosynthetics 
Fig. 2 Soil grain size distribution: Samples 1 and 2

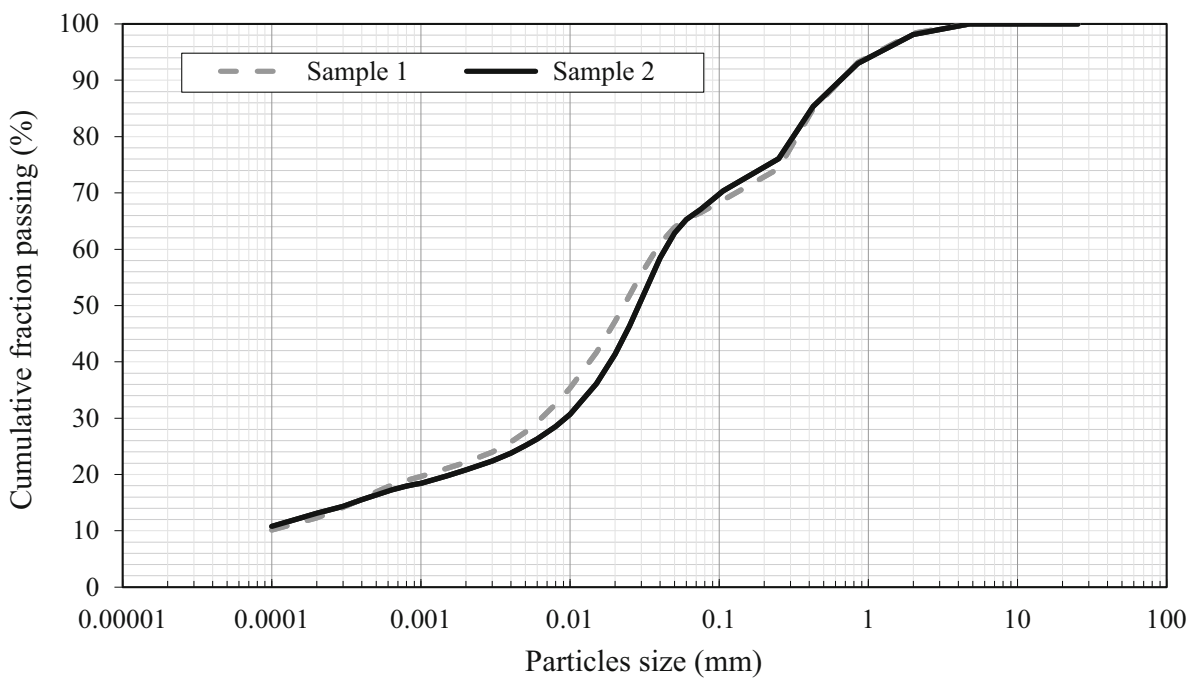

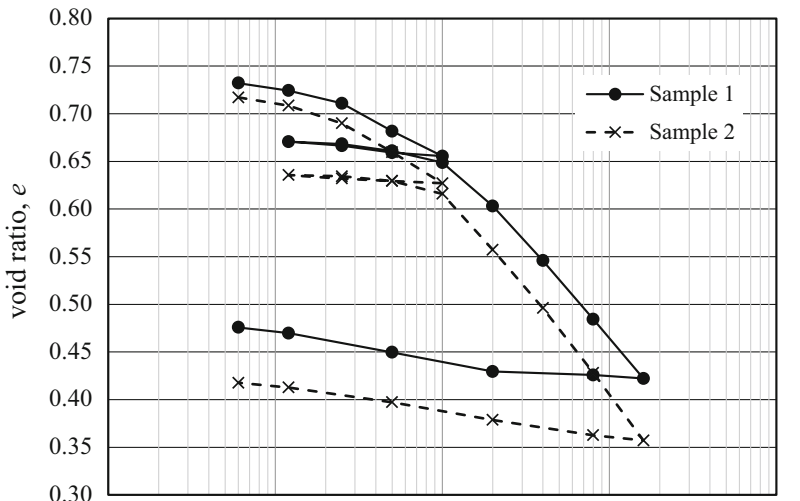
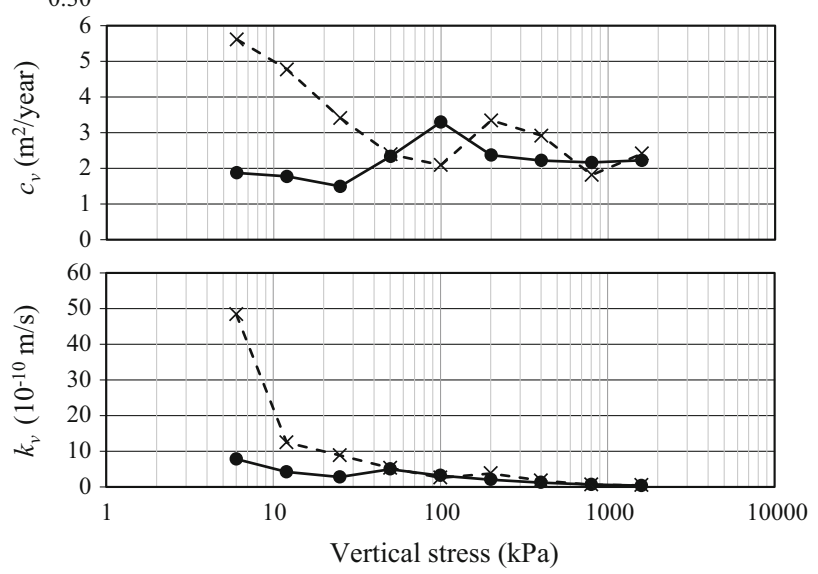

Fig. 3 Oedometer consolidation test results

were recovered for testing, assessing their permittivity. In all tests the flow was laminar, confirmed using Reynolds and Froude numbers.

The permeability tests (Fig. 4a) allowed estimating the time for the water to seepage through the model. A normal stress of $2.2 \mathrm{kPa}$ was applied to the top of the model, to help preventing movement of the upper layer of reinforcement. After building the model the water level was raised (upstream) until it reached the mid height of the upper reinforced soil layer $\left(h_{\mathrm{b}}+h_{\mathrm{r}}+h_{t} / 2\right.$ from the flume's base). As the model absorbed water, the upstream water level was re-established periodically. The maximum test duration was $6 \mathrm{~h}$ and the test was stopped when seepage occurred. The evolution of the free water surface on the model lateral planes (in contact with the flume) was marked.

The aim of the lateral and frontal erosion tests (Fig. 4b) was to recreate erosive actions due to water flow typical of the Aveiro lagoon: water flow on a channel can induce lateral erosion; additional frontal erosion can be due to channels perpendicular to the walls or to openings in parallel walls, resulting in water flow from another salt pan. The average water velocity on the smaller section adjacent to the model was $0.75 \mathrm{~m} / \mathrm{s}$. Due to the difficulty in visualising the changes induced by the water flow, the flow was stopped every $30 \mathrm{~min}$ to observe the occurring changes. This can have also led to aggravating the test conditions. The tests were stopped when the model failed.

Other models were submitted to overtopping (Fig. 4c). To allow for enough space for the water flow, the total height of the models was reduced (Table 5). The water flow was established until it overtopped the model. The flow was maintained constant (velocity of $0.33 \mathrm{~m} / \mathrm{s}$ ) until the model failed.

\section{Results and Discussion}

\section{Tests in the Flume}

Table 6 summarises the observations from the flume tests: schematic configuration and image of the models at the end of the tests and, when applicable, duration of the tests $(d)$. 
Table 4 Tensile and hydraulic properties of the geosynthetics (data for geogrid GGR and geocomposite GCR previously presented in Rosete et al. [6])

Table 5 Dimensions of the models used in the flume

\begin{tabular}{|c|c|c|c|c|c|c|c|c|}
\hline \multirow[t]{2}{*}{ Geosynthetic } & \multicolumn{4}{|c|}{ EN ISO 10319 [7] } & \multicolumn{2}{|c|}{ EN ISO 11058 [9] } & \multicolumn{2}{|c|}{ EN ISO 12956 [10] } \\
\hline & $T(\mathrm{kN} / \mathrm{m})$ & CV (\%) & $\varepsilon_{\mathrm{f}}(\%)$ & $\mathrm{CV}(\%)$ & $\psi\left(\mathrm{s}^{-1}\right)$ & CV (\%) & $O_{90}(\mu \mathrm{m})$ & $\mathrm{CV}(\%)$ \\
\hline GGR & 44.4 & 1.6 & 8.1 & 6.0 & - & - & - & - \\
\hline GCR & 54.6 & 2.8 & 10.6 & 4.1 & 1.27 & 4.2 & 207.8 & 1.8 \\
\hline GTX & 12.8 & 6.8 & 65.2 & 11.72 & - & - & 76 & - \\
\hline GGR+GTX & - & - & - & - & 0.29 & 12.67 & - & - \\
\hline
\end{tabular}

\begin{tabular}{llllllll}
\hline Test & $h_{\mathrm{b}}(\mathrm{m})$ & $h_{\mathrm{r}}(\mathrm{m})$ & $h_{t}(\mathrm{~m})$ & $l_{\mathrm{a}}(\mathrm{m})$ & $H(\mathrm{~m})$ & $B(\mathrm{~m})$ & $L(\mathrm{~m})$ \\
\hline Permeability & 0.04 & 0.30 & 0.08 & 0.35 & 0.42 & 0.40 & 1.00 \\
Erosion & 0.02 & 0.30 & 0.04 & 0.35 & 0.36 & 0.20 & 1.00 \\
Overtopping & 0.04 & 0.25 & 0.06 & 0.45 & 0.35 & 0.40 & 1.00 \\
\hline
\end{tabular}

For the permeability tests, a global value of the coefficient of permeability $(k)$ is also included. After the permeability and overtopping tests, the permittivity $(\psi)$ of the association of geogrid GGR and geotextile GTX (GGR+GTX) was determined and compared with that of the association GGR+GTX before the flume test.

The flume permeability tests allowed estimating the time necessary for the water to pass through the reinforced soil layer, enabling comparing the different solutions studied for their macroscopic (global) permeability. Most values are of the same order of magnitude $\left(10^{-5} \mathrm{~m} / \mathrm{s}\right)$, the exception was the model reinforced with geogrid GGR $\left(10^{-4} \mathrm{~m} / \mathrm{s}\right)$. All values are higher than the estimates for the soil measured from the results of the oedometer tests $\left(0.36 \times 10^{-10}\right.$ to $\left.48.3 \times 10^{-10} \mathrm{~m} / \mathrm{s}\right)$. There are different factors contributing to these differences. On one hand, although all samples were remoulded, on the oedometer tests the flow was vertical, while on the flume it was horizontal. On the other hand, it is likely that the reinforcement acted as an entrance point for the water. The lowest permeability was found for the association of geogrid GGR and geotextile GTX (GGR+GTX), which enabled water to pass through the reinforcement in a longer period. Geogrid GGR has no drainage capacity, yet it allowed the water to seepage at a higher rate than the remaining solutions, namely the unreinforced. The blue lines included on the schematic representations (Table 6) show how the water level evolved during the test. Likely, the upper horizontal layer of reinforcement (with low confining stress) allowed the water to enter the soil.

The lower performance of the solutions without reinforcement and using geogrid GGR are mostly due to the transition between compacted layers of the fine soil (Fig. 5). These enabled localised areas of different permeability. The compaction of the fine soil, even if done in several layers, was not homogeneous along the height of the model. Additionally, due to the position of the person preparing the model relatively to the flume (during soil compaction), one side was less compacted (Fig. 5). This was observed for all models and it is not likely to affect them differently. Although this is an experimental flaw, it highlights problems likely to occur on site, where ensuring uniform compaction in large areas can prove even more difficult.

During the experimental program, the soil was always covered with plastic films to minimise changes in water content. After preparation to the desired water content, the soil was placed on the flume. The water content of the models was controlled to ensure the desired values were met. However, it was very difficult to ensure the water content of each model was homogeneous. Again, this is likely to occur on site, and at a higher scale.

For models reinforced with geogrid GGR there was an additional effect: the lumps of soil particles could not enter the geogrid openings; therefore, a layer of looser soil adjacent to the geogrid, and thus more permeable, was created. For the solutions where a sheet geosynthetic was used (geocomposite GCR and association of GGR+GTX) such phenomena had less impact, as most soil was enveloped by the reinforcement. Nevertheless, as mentioned before, the upper horizontal layer of reinforcement allowed water to enter the model.

The permittivity of GGR+GTX before and after the flume permeability tests was assessed, to identify if there was clogging of the reinforcement. After seepage the permittivity of GGR+GTX was $0.22 \mathrm{~s}^{-1}$ (coefficient of variation of $18 \%$ ), $25 \%$ smaller than the initial value. The scatter of results is important, reflecting the heterogeneity of such clogging, even after the flume tests, which were performed under controlled conditions. These results also indicate that a significant clogging of the reinforcement (the geotextile) is likely, which tends to reduce the permeability of the reinforced soil layer. Before the permittivity tests the specimens were not cleaned, however, 

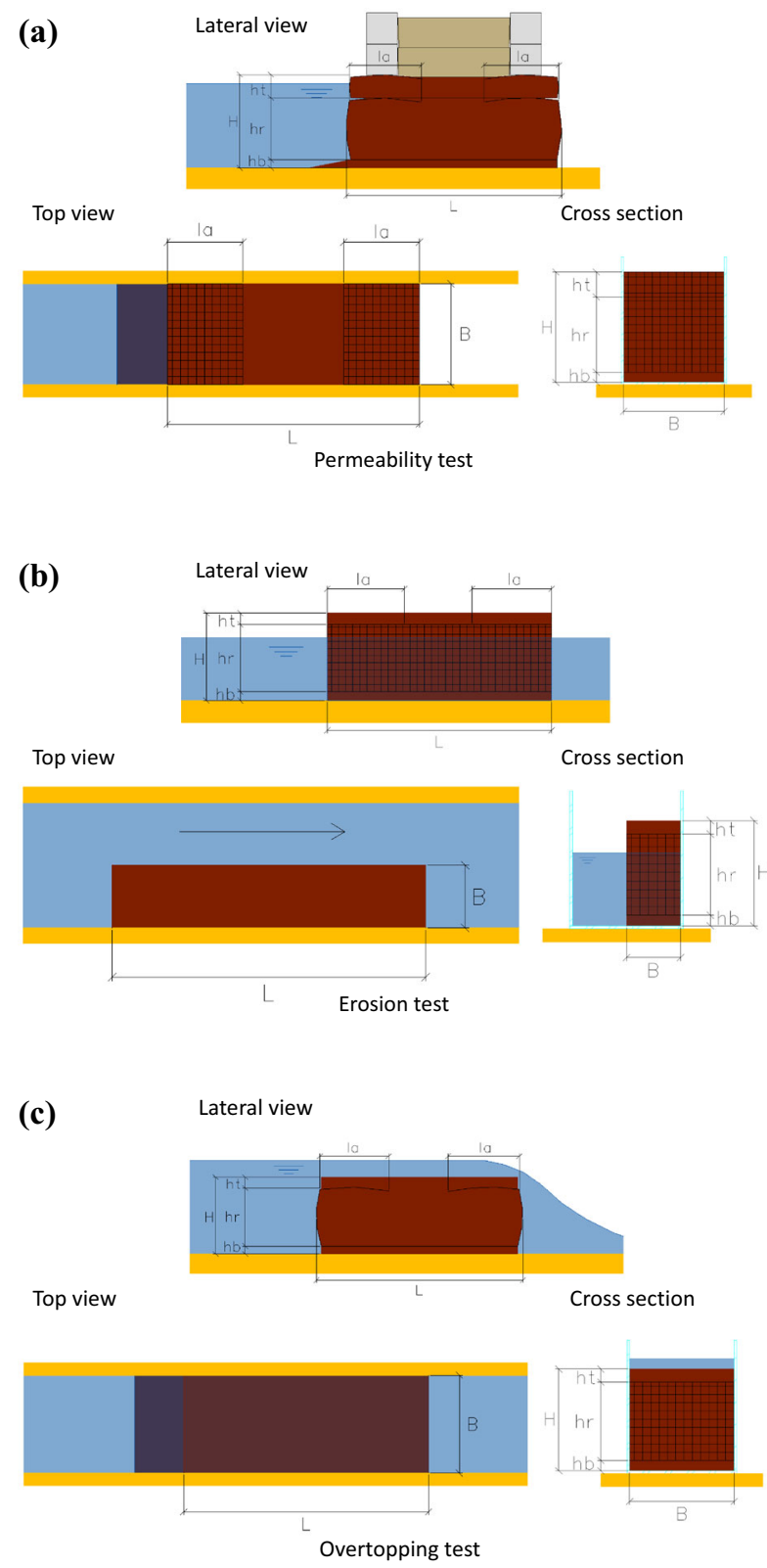

Fig. 4 Schematic representation of the models used for the flume tests: a permeability, b erosion, $\mathbf{c}$ overtopping

according to the relevant standard [9], they were submerged in water for $12 \mathrm{~h}$. As this may have contributed to releasing some of the clogging particles, the relevance of the clogging may be higher than estimated from the test results.

All models submitted to lateral and frontal erosion tests exhibited a tilting failure. This was due to the test set-up, as a lower layer of compacted (unreinforced) fine soil was included (Fig. 4b). This layer was eroded and enabled the reinforced soil layer to rotate and fail (Table 6). The time until failure was recorded and compared. While models with sheet reinforcement (geocomposite GCR and association of geogrid GGR and geotextile GTX) had a tilting or overturning failure, when geogrid GGR was used there was also some erosion of soil inside the reinforcement (Table 6). The results indicate that using reinforcement improved the resistance to lateral and front erosion of the soil, even for geogrid GGR (which allowed for erosion of the enveloped soil).

The overtopping tests carried out in the flume had to be stopped because, for the reinforced solutions, the model failed by erosion of the top soil layer (unreinforced), leading to the release of the reinforcement. This erosion was not the same on both sides of the model and, was consistently more important on the same side. These differences are likely to be caused by the issues with the compaction procedure, described for the permeability tests. The larger erosion rate observed for GTX+GGR was probably caused by a lower water content of the soil (13\%) when the test was set-up, comparatively to the other solutions tested $(15 \%)$. The unreinforced soil was significantly eroded downstream. Although the reinforced models failed within a shorter period, the erosion was not as important. These results seem to indicate that, providing adequate anchoring of the geosynthetic is ensured, the reinforcement provides additional resistance to erosion due to overtopping.

\section{Comparison with the Traditional Solution}

Carlos et al. [1] reported similar flume tests on the material traditionally used to build the walls. The traditional material (Fig. 6) was classified as an organic clay (ASTM D2487-11 [20]), with $42 \%$ silt and $26 \%$ clay particles, $w_{\mathrm{L}}=156 \%, w_{\mathrm{P}}=95 \%$ and $I_{\mathrm{P}}=61 \%$. The unit weight of the soil was $10.7 \mathrm{kN} / \mathrm{m}^{3}$ and its natural water content was $404 \%$. Prior to the permeability test, the traditional soil was immersed in water for $24 \mathrm{~h}$. After 7 days of testing there was no significant seepage through the soil, although it had absorbed some water. The traditional soil was found practically impermeable. Therefore, if these results are representative of the conditions in the lagoon, the traditional solution is likely to be much less permeable than the reinforced models tested. To meet the structure requirements the solutions proposed need to be revised, in order to meet the permeability criteria. The traditional material consists of a soil matrix with reed and was used as collected from the lagoon (not compacted). The plants and their roots are entangled and provide agglutination of the soil particles. Additionally, the reed is likely to contribute for maintain high moisture levels on the soil, thus becoming less prone to the entrance of water.

The lateral and frontal erosion test of the traditional material (24 h long) caused damage to the soil, releasing some roots and soil from the block, especially with the first 
Table 6 Summary of observations from the flume test: schematic configuration of the models at the end of the tests, image of the models at the end of the tests, global value of the coefficient of permeability $(k)$ and duration of the tests $(d)$

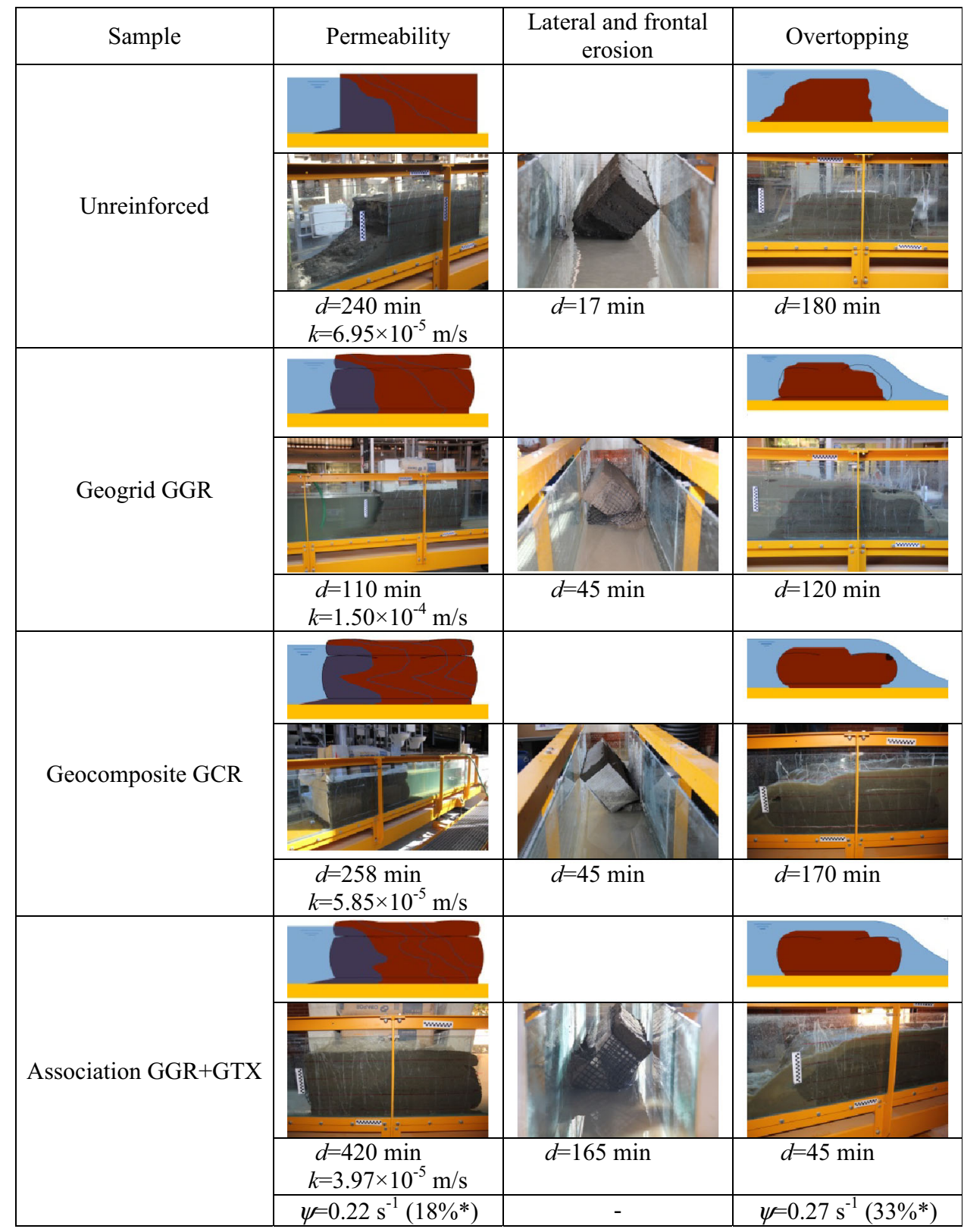

* Coefficient of variation, in percentage

impact of water. Carlos et al. [1] also reported that the water flow worn out the blocks, noticeably leaving more exposed roots. This may help explaining the significant erosion occurring on the traditional walls when there is flow normal to the wall, affecting it directly, creating or amplifying existing openings. Contrary to what was observed for the models with geosynthetics, the traditional material did not fail. The traditional material is reinforced with natural fibres (reed and its roots) which are spread out through the soil matrix. This increases the resistance to erosion.

Carlos et al. [1] submitted the traditional material to a flume test to simulate overtopping and the presence of discontinuities (represented by the contact between two adjacent soil blocks and some small space between the block and the flume walls). The authors reported that the flow parallel to the discontinuities caused large erosion on 


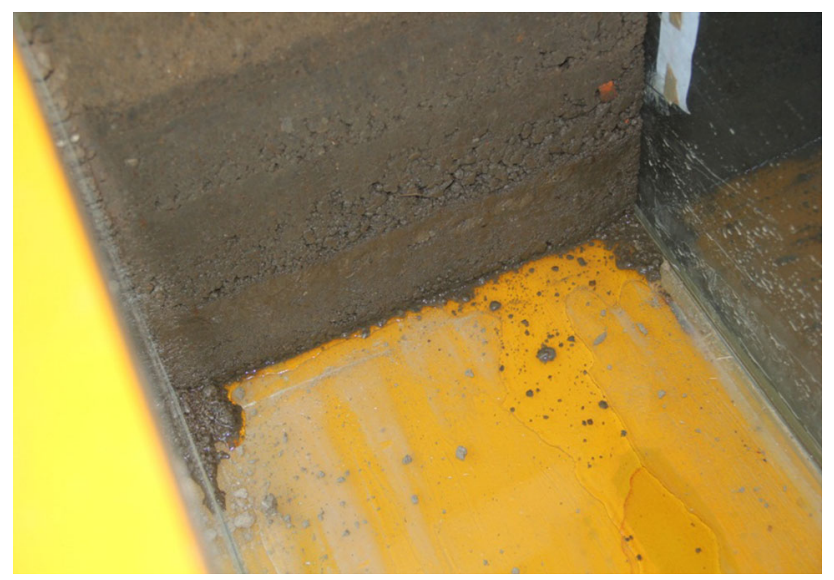

Fig. 5 Layering of the soil after compaction, creating singularities

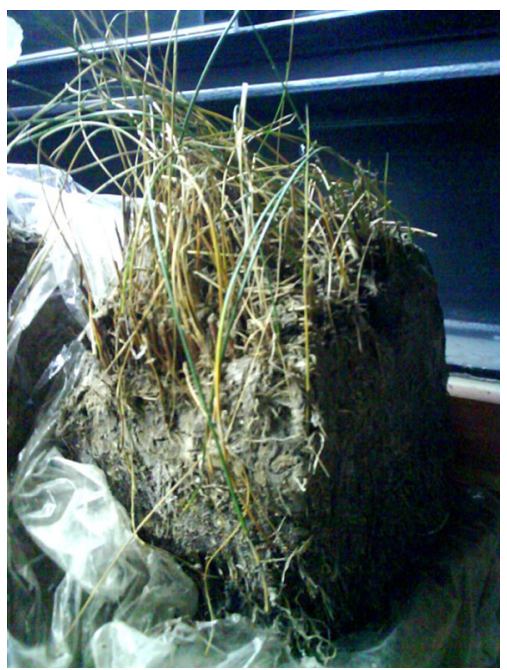

Fig. 6 Traditional material used to build the salt pan walls

the block, due to the punctual high velocities observed, producing erosion even with the block surface covered by reed. However, the areas far from the discontinuities performed much better. This showed that this particular vegetation seems to protect the traditional material from erosion when there is overtopping of the walls (without discontinuities). The random distribution of the fibre reinforcement on the traditional material prevented the type of failures observed on the models reinforced with geosynthetics, where insufficient anchoring of the geosynthetics was crucial for the stability of the models.

The different response observed for the traditional soil and the reinforced soil models is likely to be caused mostly by the different soils (Table 3; [1]). For example, their Atterberg limits, natural water content and unit weight are very different. Therefore, the type of reinforcements (natural fibres or geosynthetics) is not the main reason for the differences observed. The availability of reed in the lagoon is very low. To enable a cost effective repair and construction of walls, local material (from each salt pan) should be used. Thus, solutions with lower permeability and higher resistance to erosion and overtopping are needed. Using fibre reinforcement, randomly distributed within the soil matrix, can be part of the solution.

\section{Conclusions}

This paper reports exploratory work on the behaviour of fine soil reinforced with geosynthetics under hydraulic actions using flume tests. The case study was a typical cross section of the salt pans walls of the Aveiro lagoon, Portugal. Solutions using the local fine soil reinforced with geosynthetics were studied. A preliminary design of a structure was done, for different reinforcements. Local soil was collected and characterised using laboratory tests. The performance of reinforced soil models (with three different reinforcements) was analysed using flume tests, considering actions typical of a lagoon environment. From the results, the following conclusions can be established:

- Some drawbacks of using geogrid GGR were identified; the models exhibited the highest global coefficient of permeability, due to the difficulty of soil lumps to penetrate the openings of the geogrid (creating areas of larger permeability); low resistance to erosion was observed, as the water washed soil particles through the grid openings.

- Sheet reinforcements enabled containing the soil, improving the response of those reinforced soil layers in the flume.

- When building the models the soil compaction and the water content were not uniform. Therefore, the permeability of the soil was not uniform. Although this is a limitation of the experimental work performed, it highlights how this can also occur on site, where ensuring uniform conditions for the soil can be quite difficult, particularly when compacting fine soils.

- The permittivity of the composite GGR+GTX showed that some clogging of the reinforcement after tests on the flume is likely, due to the decrease in permeability associated with seepage.

- The solutions using geosynthetics were compared with similar data from the literature for the traditional material used to build the salt pans walls. The traditional material consists of a soil matrix and reed. The permeability of the traditional solution is significantly lower than for all other models tested. This is likely to be related primarily with different soils used and secondarily with the random location of the plants (natural fibre reinforcement) on the traditional solution. 
The traditional material also exhibited higher resistance to the erosive actions and overtopping.

- The results indicate that a possible alternative solution for the walls could use fibre reinforcement. Due to the current limited availability of reed, the reinforcements could either be synthetic (although vegetation growth should be promoted to avoid surface erosion), or natural (provided adequate effective and sustainable alternatives to reed can be identified). Additionally, solutions for the walls need to ensure adequate (low) permeability.

Acknowledgments The authors would like to thank the financial support of FCT, Research Project PTDC/ECM/099087/2008 and COMPETE, Research Project FCOMP-01-0124-FEDER-009724.

\section{References}

1. Carlos D, Pereira M, Costa S, Pinho-Lopes M, Coelho C (2011) Walls of the Saltpans of the Aveiro Lagoon, Portugal-current status and proposed new solutions using geosynthetics. J Coast Res SI64:1467-1471

2. Lopes CL, Dias JM (2015) Assessment of flood hazard during extreme sea levels in a tidally dominated lagoon. Nat Hazards. doi:10.1007/s11069-015-1659-0

3. Dias JM, Lopes CL, Coelho C, Pereira C, Alves FL, Sousa LP, Antunes IC, Fernandes MD, Phillips (2014) Influence of climate change on the Ria de Aveiro littoral: adaptation strategies for flooding events and shoreline retreat. J Coast Res SI70:320-325

4. Lopes CL, Dias JM (2014) Influence of mean sea level rise on tidal dynamics of the Ria de Aveiro lagoon, Portugal. J Coast Res SI70:574-579

5. Carlos DM, Pinho-Lopes M (2011) Reinforcement with geosynthetics of walls of the saltpans of the Aveiro lagoon. Geotech Geol Eng 29:519-536

6. Rosete A, Mendonça-Lopes P, Pinho-Lopes M, Lopes ML (2012) Tensile and hydraulic properties of geosynthetics after mechanical damage and abrasion laboratory tests. Geosynth Int 20(5):358-374
7. EN ISO 10319:2008 Geosynthetics. Wide-width tensile test. BSI, London

8. EN ISO 9863-1:2005 Geosynthetics. Determination of thickness at specified pressures. Single layers. BSI, London

9. EN ISO 11058:2010 Geotextiles and geotextile-related products-determination of water permeability characteristics normal to the plane, without load. BSI, London

10. EN ISO 12956:1999 Geotextiles and geotextile-related products. Determination of the characteristic opening size. BSI, London

11. Bonito FAB (2008) Rheology of sludge and other recent sediments of Ria de Aveiro. PhD dissertation, University of Aveiro, Portugal (in Portuguese)

12. Gomes LMF (1992) Geotechnical zoning from urban and suburban area of Aveiro. $\mathrm{PhD}$ dissertation, University of Aveiro, Portugal (in Portuguese)

13. Rogbeck Y, Alén C, Franzén G, Kjeld A, Odén K, Rathmayer H, Watn A, Oiseth E (2003) Nordic guidelines for reinforced soils and fills. [Revision A-February 2004]. Nordic Geosynthetic Group, p 204

14. EN 1990:2002 Eurocode—basis of structural design. BSI, London

15. EN 1997-1:2004 Geotechnical design. Part 1: general rules. BSI, London

16. ISO/TS 17892-5:2004 Geotechnical investigation and testinglaboratory testing of soil. Part 5: incremental loading oedometer test. ISO, Geneva

17. ASTM D 1557-12 Standard test methods for laboratory compaction characteristics of soil using modified effort $(56,000 \mathrm{ft}-\mathrm{lbf} /$ $\left.\mathrm{ft}^{3}\left(2,700 \mathrm{kN}-\mathrm{m} / \mathrm{m}^{3}\right)\right)$. ASTM International, West Conshohocken

18. ISO/TS 17892-8:2004 Geotechnical investigation and testinglaboratory testing of soil. Part 8: unconsolidated undrained triaxial test. ISO, Geneva

19. ASTM D 1883-07 Standard test method for CBR (California Bearing Ratio) of laboratory-compacted soils. ASTM International, West Conshohocken

20. ASTM D 2487-11 Standard practice for classification of soils for engineering purposes, ASTM International, West Conshohocken

21. AASHTO M 145-91-UL (2004) Classification of soils and soilaggregate mixtures for highway construction purposes, American Association of State Highway and Transportation Officials, Washington DC

22. Alves ILD (2012) Muros em solo reforçado com geossintéticosanálise experimental. Integrated Master dissertation, Univeristy of Aveiro, Portugal (in Portuguese) 